DOI: $10.5007 / 2175-7941.2013 v 30 n 3 p 628$

\title{
APRENDIZAGEM CIENTÍFICA INFORMAL NO PIBID: IDENTIFICANDO E INTERPRETANDO OS $\mathrm{FOCOS}^{+*}$
}

Thomas Barbosa Fejolo

Programa de Pós-Graduação em Ensino de Ciências e

Educação Matemática - UEL

Sergio de Mello Arruda

Departamento de Física - UEL

Marinez Meneghello Passos

Departamento de Matemática - UEL

Londrina - PR

\section{Resumo}

Este artigo apresenta resultados de uma investigação sobre a aprendizagem científica informal no contexto do Programa Institucional de Bolsas de Iniciação à Docência (PIBID). Tomamos como referência os focos do aprendizado científico informal (FAC), que representam seis dimensões da aprendizagem, a saber: 1) Desenvolvimento do interesse pela ciência; 2) Compreensão de conhecimento científico; 3) Engajamento em raciocínio científico; 4) Reflexão sobre a ciência; 5) Engajamento na prática científica; 6) Identificação com a ciência. Para o levantamento de dados utilizou-se o registro em filmagem das interações e diálogos de estudantes de graduação, enquanto realizavam atividades de espectroscopia em laboratório de óptica. Com base nos procedimentos da Análise de Conteúdo e por meio das interpretações das falas, investigamos quais dos seis focos estiveram presentes durante a

\footnotetext{
${ }^{+}$Informal Science learning in PIBID: identifying and interpreting the strands

* Recebido: março de 2013.

Aceito: julho de 2013.
} 
ação dos estudantes nas atividades. Como resultado traçamos um perfil de aprendizagem para cada estudante, distribuindo as comunicações nos diferentes focos do aprendizado cientifico informal.

Palavras-chave: Aprendizagem Cientifica Informal. Espectroscopia. Análise de Conteúdo. Física Moderna. PIBID.

\begin{abstract}
This paper presents a research on informal Science learning in the context of the Institutional Scholarship Program Initiation to Teaching (PIBID). We take as reference the strands of informal Science learning $(F A C)$, representing six dimensions of learning, they are: 1) Development of interest in Science; 2) Understanding of scientific knowledge; 3) Engaging in scientific reasoning; 4) Reflection on Science; 5) Engagement in scientific practice; 6) Identification with Science. For the lifting data, it was used the filming record of the interactions and dialogues of undergraduate students while performing activities of Optical Spectroscopy in the laboratory. Based on the procedures of content analysis and interpretations through communication, we investigate which of the six strands were present during the action of the students in activities. As a result we have drawn a learning profile for each student by distributing communications in different strands of informal Science learning.
\end{abstract}

Keywords: Informal Science Learning. Spectroscopy. Content Analysis. Modern Physics. PIBID.

\title{
I. Introdução
}

Os temas que envolvem a aprendizagem científica são frequentemente abordados em pesquisas da área de Ensino de Ciências. Pesquisadores já se dedicaram a investigar o assunto utilizando múltiplos enfoques, entre eles estão os que priorizam: 1) Os ambientes em que ocorrem as aprendizagens (FALK; DIERKING, 2000; BANKS et al., 2007); 2) Como os estudantes aprendem (POSNER et al., 1982; MORTIMER, 1995; DUIT; TREAGUST, 2003; ARRUDA et al., 2004; 
QUEIROZ; LIMA, 2007; LABURÚ; SILVA, 2011); 3) Os conteúdos abordados nestas situações (OSTERMANN; MOREIRA, 2000) etc.

O contexto desta investigação é o Programa Institucional de Bolsas de Iniciação à Docência (PIBID). Consideramos o PIBID como uma configuração informal de aprendizagem, ou seja, como um projeto que articula uma relação entre a universidade e a escola, mas que não partilha das características da educação formal, que é aquela que se desenvolve em uma instituição de educação como uma escola ou uma universidade, é estruturada em termos de objetivos, currículo, tempo de aprendizado etc., e que leva obrigatoriamente a uma certificação (EUROPEAN COMMISSION, 2001, p. 32). Conforme definido no NRC (2009), as configurações de aprendizagem informal incluem a aprendizagem no dia a dia, em espaços planejados (museus, centros de ciência) ou programas que ocorrem fora da escola ou para adultos (NRC, 2009, p. 47-48). Por essa razão optamos por considerar o PIBID como um programa para adultos, dotado de objetivos (às vezes não muito claros para os participantes), com alguma estrutura previamente estabelecida, mas que possui a característica fundamental da aprendizagem informal, a participação voluntária.

Em configurações como essa, é comum encontrarmos os diálogos de ensino e de aprendizagem informal ou DIAI, conforme definido em Arruda et al. (2013). Proveniente das comunicações entre as pessoas, os DIAI podem ocorrer em qualquer lugar e em situações diversas: nos ambientes informais cotidianos, nos programas, nas discussões entre os pares, na realização de atividades etc. Nesta investigação buscamos encontrá-los nas comunicações ocorridas entre dois bolsistas do PIBID, ao longo de suas atividades em laboratório de espectroscopia. Cabe esclarecer que bolsistas do PIBID são estudantes da graduação (neste caso da licenciatura em Física) que recebem uma bolsa mensal para desenvolverem atividades relativas a este programa de iniciação à docência.

Adjacente aos DIAI, trabalhamos com a ideia dos focos do aprendizado cientifico informal (FAC), que podem ser definidos como categorias que ressaltam diferentes dimensões da aprendizagem de ciência (ARRUDA et al., 2013) - 1) Desenvolvimento do interesse pela ciência; 2) Compreensão de conhecimento científico; 3) Engajamento em raciocínio científico; 4) Reflexão sobre a ciência; 5) Engajamento na prática científica; 6) Identificação com a ciência. Os instrumentos de avaliação da aprendizagem geralmente são elaborados para identificar se os sujeitos captaram os conteúdos, os significados, os conceitos etc. Neste sentido, acreditamos que os FAC ampliam a discussão sobre a aprendizagem, consequentemente sobre a avaliação, pois além de abordar a aprendizagem dos conteúdos e dos modelos científicos, incluem aspectos como o interesse pela ciência, a reflexão 
sobre a ciência, o raciocínio científico, o envolvimento com a prática científica e a identificação com a ciência.

Os seis FAC foram propostos em um relatório americano denominado por Learning Science in Informal Environments: People, Places, and Pursuits (NRC, 2009). O conjunto de categorias incorpora diversos resultados de pesquisa, e foram utilizados para avaliar a aprendizagem dos sujeitos nos diferentes contextos e configurações de aprendizagem.

O documento do National Research Council (NRC) mencionado anteriormente faz ampla revisão de trabalhos relacionados à aprendizagem cientifica em ambientes informais e foi elaborado por um comitê de pesquisadores sob a coordenação geral do National Research Council dos Estados Unidos da América. No que tange às nossas pesquisas, um dos pontos que mais nos chamou a atenção neste relatório foi a apresentação dos strands of science learning (NRC, 2009, p.4 e p.43), que articulam um conjunto de seis habilidades cientificas específicas associadas à aprendizagem em ambientes informais. Em nossas produções - por dificuldades de tradução - optamos por denominar este conjunto de habilidades de focos da aprendizagem cientifica (ARRUDA; PASSOS; FREGOLENTE, 2012, p. 26).

Portanto, a questão que se coloca neste artigo é a seguinte: é possível identificar nos diálogos de aprendizagem informal (DIAI), realizados pelos acadêmicos (bolsistas do PIBID) no laboratório, as evidências de aprendizagem científica $(\mathrm{FAC})$ ?

A pesquisa, cujos resultados apresentamos neste artigo, tem como objeto de análise os diálogos desses graduandos da licenciatura em Física de uma universidade pública do estado do Paraná. Os acadêmicos realizaram experimentações envolvendo conteúdos de Física Moderna em um laboratório de espectroscopia dessa universidade e todas as atividades, referentes a este projeto, de que eles participaram foram capturadas em vídeo. Posteriormente à transcrição de todos os diálogos ocorridos durante a realização dos experimentos, buscamos investigar o aprendizado científico informal por meio da análise dos discursos dos participantes (sujeitos da pesquisa). Os seis focos, enunciados anteriormente, nos serviram como categorias a priori de investigação e serão retomados com mais detalhes na próxima seção. 


\section{Os focos do aprendizado científico informal}

Aprender ciência é se envolver com este amplo conjunto de aspectos relacionados nesses focos do aprendizado, que foram traduzidos diretamente do relatório (NRC, 2009). Após a tradução e a leitura desse documento produzimos um resumo de cada foco e a seguir trazemos os significados relativos a cada um deles.

Foco 1: Desenvolvimento do interesse pela ciência

Refere-se ao envolvimento emocional, ao interesse, à mobilização e à motivação do estudante para aprender ciência. As participações em ambientes atraentes e estimulantes podem despertar a curiosidade, a admiração e dar suporte à aprendizagem científica (NRC, 2009, p.43).

Foco 2: Compreensão de conhecimento científico

Está relacionado à aprendizagem das principais teorias e dos modelos científicos. Os estudantes conseguem explicar fenômenos do mundo natural utilizando linguagem científica, conceitos e conteúdos que são produtos do conhecimento científico. Fazem parte do processo de aprendizagem as atividades que vão desde perceber, argumentar, utilizar linguagem científica, explicar e articular novos fenômenos, até gerar, compreender, adquirir, lembrar e utilizar os modelos científi$\cos (\mathrm{NRC}, 2009, \mathrm{p} .44)$.

Foco 3: Engajamento em raciocínio científico

Enquadram-se neste foco as ações que remetem ao aprendizado do processo de fazer ciência, algumas delas são: formular e responder perguntas, realizar observações e experimentações, formular e testar hipóteses, elaborar modelos explicativos, explorar as consequências dos resultados encontrados, realizar previsões com base em dados observacionais ou teóricos, inclusive aqueles relacionados aos fenômenos do dia a dia; enfim, compreender todo o processo de geração e de avaliação de evidências, que estão no centro dos procedimentos científicos (NRC, 2009, p.44)

Foco 4: Reflexão sobre a ciência

O foco circunscreve tudo que se refere à reflexão sobre a ciência, a compreensão da ciência como um empreendimento cultural, social e temporal. Saber da história das ideias científicas, das múltiplas teorias, seus métodos e ferramentas. Melhorar a compreensão sobre o que é a ciência, conhecendo mais sobre a epistemologia e o desenvolvimento do conhecimento científico. Ainda faz parte deste foco de aprendizagem conhecer o seu próprio estado de conhecimento, como foi 
adquirido e como pode mudar concepções prévias que estão em desacordo com as concepções científicas (NRC, 2009, p.45). É importante ressaltar as diferenças entre os focos 2,3 e 4 : o foco 2 diz respeito ao conhecimento científico propriamente dito, o foco 3 trata da ciência enquanto processo e o foco 4 enfatiza a meta-análise, ou seja, a reflexão, a análise crítica tanto sobre a natureza do conhecimento quanto do seu aprendizado. É o momento em que o sujeito se afasta do que sabe e avalia se pode atribuir valor de verdade ao seu próprio conhecimento sobre os fenômenos.

Foco 5: Engajamento na prática científica

Pessoas atraídas pela ciência se matriculam voluntariamente em programas, eventos científicos etc. Este foco está relacionado ao engajamento do estudante em uma comunidade científica, com a qual ele aprende sobre a utilização de ferramentas e as normas científicas, as atividades e as práticas científicas realizadas por um grupo de pessoas interagindo, conversando, explorando e se divertindo. Neste engajamento alguns participantes chegam a argumentar de maneira científica sobre um problema ou fenômeno (NRC, 2009, p.46). A ênfase do foco 5 recai sobre a natureza da ciência, enquanto uma prática desenvolvida por uma comunidade, que dá o aval e ensina sobre quais são os conteúdos científicos, os procedimentos e as análises críticas relevantes sobre determinado campo do conhecimento científico.

Foco 6: Identificação com a ciência

Atividades educacionais podem ajudar as pessoas a desenvolverem sua identidade enquanto cientista. $\mathrm{O}$ estudante pode ver a si mesmo como aprendiz de ciência, sentindo-se confortável e interessado por ela. Sentimentos de pertencimento, participação progressiva em atividades e a escolha profissional são importantes evidências de identificação (NRC, 2009, p.46).

Consideramos que pensar a aprendizagem científica como um processo que envolve seis dimensões é ultrapassar os limites da aprendizagem científica dos conteúdos (o foco 2 é comumente a dimensão mais almejada pelos professores de ciência das escolas e das universidades). Outros tipos de aprendizagem podem dar suporte ao foco 2, como por exemplo: o interesse, o raciocínio, a reflexão, a prática e a identificação do estudante com a ciência.

Em resumo: o foco 1 está relacionado com a motivação, a mobilização, a emoção, a curiosidade, a admiração para a ciência etc.; o foco 2 é relativo à aprendizagem do conteúdo, da linguagem, dos modelos e das teorias científicas etc.; o foco 3 leva em consideração a formulação de perguntas, a exploração e a explica- 
ção de ideias e das teorias, o raciocínio lógico do estudante etc.; o foco 4 é aquele vinculado ao envolvimento do estudante com a história da ciência, com a epistemologia, com a reflexão sobre a ciência etc.; o foco 5 diz respeito ao engajamento em atividades práticas, ao uso de ferramentas e das normas científicas e à participação do estudante em comunidades científicas etc.; e o último foco - foco 6 - tem relação com a identidade do estudante para com a ciência, com o pertencimento e o conforto com a ciência, e a participação progressiva em atividades relativas e ela etc.

Todavia, cabe observar que os FAC se interceptam e se complementam nos processos de aprendizagem científica. O progresso do estudante em um deles contribui com o desenvolvimento dos demais (NRC, 2009, p.47). Este progresso não obedece absolutamente à ordem numérica conforme foram apresentados, ou seja, eles não avançam em sequência, no entanto, integram todo o processo.

\section{III. $O$ contexto da pesquisa}

O PIBID é um programa financiado pela Coordenação de Aperfeiçoamento de Pessoal de Nível Superior (CAPES), com o objetivo de incentivar a formação de professores para a Educação Básica. Uma de suas principais ações é o fornecimento de bolsas para estudantes das licenciaturas, para que esses possam aprender sobre a profissão docente atuando diretamente nas escolas parceiras, sob a supervisão de um professor dessas escolas (BRASIL, 2010). Esta investigação se desenvolveu focalizando dois bolsistas do PIBID, da modalidade iniciação à docência, estudantes de licenciatura em Física.

Esses estudantes promoveram encontros semanais que tiveram como objetivo a produção e o planejamento de aulas sobre Física Moderna que, posteriormente, seriam (e foram) ministradas por eles em uma turma do ensino médio e que possuía como professor um professor-supervisor, também integrante do PIBID. Essa proposta em pesquisa foi realizada em dois momentos: primeiro a preparação e o planejamento de aulas, que envolvia estudos do conteúdo e atividades em laboratório desenvolvidas pelos licenciados em Física (objeto investigado, cujos resultados apresentamos neste artigo) e, segundo, a ministração de aulas na escola (esta etapa que também foi captura em vídeo, será alvo de outro processo interpretativo).

Salientamos que este artigo visa identificar aprendizagens científicas informais no contexto das atividades de espectroscopia, realizadas em laboratório de óptica, em que os bolsistas se reuniam para realizar experimentos com o objetivo de preparar aulas de Física, que em momento posterior seriam ministradas. Nestas situações, investigamos se os diálogos entre esses acadêmicos revelam as dimen- 
sões de aprendizagem definidas pelos FAC. Na próxima seção apresentamos a metodologia de identificação e de interpretação desses focos.

\section{A metodologia de pesquisa e os movimentos interpretativos}

Fizemos uso de um conjunto de procedimentos para organizar e descrever as comunicações, as ações e as interações dos licenciandos no contexto investigado. Com isso, nosso primeiro contato com o material gravado em vídeo e transcrito foi por meio de uma leitura flutuante, leitura em que o principal objetivo é o de conhecer o material que se possui para o desenvolvimento da análise. Nessa leitura primeira, não tínhamos como intenção localizar as seis dimensões da aprendizagem científica, mas somente dar voz às falas dos dois bolsistas. Neste processo focamos na "enumeração das características do material" e a interpretação foi a "significação concedida a estas características" (BARDIN, 2004, p.34).

Para que esse movimento analítico fique mais claro, cabe compreender que a Análise de Conteúdo pode ser definida como uma série de procedimentos que desenvolvem a:

[...] análise das comunicações visando obter, por procedimentos sistemáticos e objetivos, de descrição do conteúdo das mensagens, indicadores (quantitativos ou não) que permitam a inferência de conhecimentos relativos às condições de produção/recepção (variáveis inferidas) destas mensagens (BARDIN, 2004, p. 37).

Contudo, esses processos que a Análise de Conteúdo nos apresenta, não devem ser tomados como um conjunto rígido de procedimentos (MORAES; GALIAZZI, 2007, p.141). Entretanto, essa falta de rigidez não implica em pouco rigor, mas permite que o pesquisador ultrapasse o olhar imediato da primeira leitura: "[...] se um olhar imediato e espontâneo já é fecundo, não poderá uma leitura atenta aumentar a produtividade e pertinência?” (BARDIN, 2004, p. 25). Três estágios são importantes nesse avanço metodológico: a pré-análise, a exploração do material e o tratamento dos dados.

A pré-análise consiste em escolher os documentos que constituirão o corpus (a matéria-prima a ser estudada, analisada), formular hipóteses sobre o fenômeno que se investiga e elaborar objetivos que conduzam a possíveis resultados. Para isso é preciso ter um conjunto de regras de recorte e de categorização que permitam a interpretação final do material e a clarificação das características do fenômeno. A exploração do material é a análise propriamente dita, em que se destaca, enumera, codifica o corpus em função das regras estabelecidas no estágio 
anterior. O tratamento dos resultados consiste primordialmente em interpretar os registros dando significação e validar o tratamento realizado mostrando a consonância desse estágio com o evento em estudo (BARDIN, 2004, p.95). Para estabelecer as relações que supomos existir entre o corpus e os seis focos do aprendizado científico, assumimos para esta investigação "o método dedutivo, um movimento do geral para o particular, que implica construir categorias antes mesmo de examinar o corpus. As categorias são deduzidas das teorias que servem de fundamento para a pesquisa" (MORAES; GALIAZZI, 2007, p.23).

O tipo de análise assumida nesta pesquisa é a categorial, porque "funciona por operações de divisão do texto em unidades, em categorias segundo reagrupamentos analógicos" (BARDIN, 2004, p.147). As categorias foram admitidas a priori e estão diretamente relacionadas com os FAC apresentados na seção anterior.

Os registros (transcrições) aqui interpretados foram capturados durante a realização de cinco encontros realizados entre os bolsistas, com duração aproximada de duas horas cada um deles. Esses encontros tinham como objetivo a montagem de experimentos que seriam depois utilizados nas aulas a serem ministradas na escola. Nessas ocasiões eles discutiam os conceitos físicos (estudados em momentos anteriores) relacionados aos fenômenos físicos implicados no experimento. Esses encontros ocorriam no laboratório de óptica do departamento de Física da universidade em que eles cursavam a licenciatura e os estudos estavam relacionados à formação e produção das Linhas de Fraunhoufer ${ }^{1}$, aos espectros de lâmpadas, à difração, à refração, à interferência, à natureza da luz e ao átomo de Bohr.

Buscamos localizar nas falas dos acadêmicos capturadas durante essas 10 horas de gravação os diálogos de ensino e de aprendizagem informal (DIAI), após isso, procuramos relacionar a esses diálogos os vários focos do aprendizado científico informal, que, em geral, se apresentam e se alternam sem uma sequência definida.

No Quadro 1, descrevemos de forma sumarizada o que foi desenvolvido nos encontros.

\footnotetext{
${ }^{1}$ A origem da espectroscopia está relacionada à presença de certas linhas escuras observadas no espectro da luz solar, um fenômeno registrado por Wollaston em 1802. Tais espectros ou decomposição da luz solar eram obtidos por meio de prismas e conhecidos desde a época de Newton. Mais tarde, em 1814, essas linhas foram redescobertas por Fraunhoufer e catalogadas segundo as letras do alfabeto (ARRUDA, 1998).
} 
Quadro 1- Encontros e atividades realizadas pelo grupo.

\begin{tabular}{|l|l|}
\hline Encontros & $\begin{array}{l}\text { Resumo das atividades de espectroscopia em laboratório de } \\
\text { óptica }\end{array}$ \\
\hline Encontro 1 & $\begin{array}{l}\text { Montagem de espectrômetro, instrumento que permite ver as li- } \\
\text { nhas espectrais de luz proveniente de lâmpadas. Neste dia foram } \\
\text { utilizadas lâmpadas compostas por Hidrogênio, Mercúrio, Hélio e } \\
\text { Neon. Foi feito o registro dos espectros em fotografia. }\end{array}$ \\
\hline Encontro 2 & $\begin{array}{l}\text { Os estudantes realizam experimentações de difração da luz utili- } \\
\text { zando lâmpadas de Hidrogênio, Mercúrio, Hélio, e desenham cada } \\
\text { espectro em folhas anotando aspectos relevantes da experiência. }\end{array}$ \\
\hline Encontro 3 & $\begin{array}{l}\text { Utilização de materiais como: rede de difração, prisma, CD. Dis- } \\
\text { cussão sobre fenômenos como a refração, o índice de refração e a } \\
\text { dispersão da luz. Utilizam conceitos físicos como comprimento de } \\
\text { onda, período, frequência. }\end{array}$ \\
\hline Encontro 4 & $\begin{array}{l}\text { Os estudantes testam a difração da luz de um laser monocromático } \\
\text { em fendas simples, em redes e em um fio de cabelo. Fotografam } \\
\text { as imagens obtidas e o aparato experimental. }\end{array}$ \\
\hline Encontro 5 & $\begin{array}{l}\text { Discussão relativa às estratégias de ensino, ao roteiro experimen- } \\
\text { tal, ao contato com materiais experimentais de baixo custo (suge- } \\
\text { ridos pelo professor-supervisor) e a orientação quanto aos conteú- } \\
\text { dos pertinentes ao planejamento das aulas a serem ministradas. }\end{array}$ \\
\hline
\end{tabular}

Ao longo dos encontros em laboratório, descritos no Quadro 1, os bolsistas do PIBID realizaram experimentos que produziram algumas imagens referentes ao fenômeno da difração da luz e que foram capturadas pelos pesquisadores e autores deste artigo. Neste momento trazemos seis delas, que contribuem com a compreensão de alguns diálogos que serão apresentados e interpretados na sequência (Fig. 1 a Fig. 6).

Todas as conversas ocorridas durante esses cinco encontros foram transcritas e analisadas. Para a construção desse artigo, trazemos somente alguns recortes desses diálogos, a título de exemplo.

Cabe destacar também que para a determinação e a seleção dos DIAI, que consideramos que são fragmentos de comunicação, foi necessário assumir o critério de pertinência ao contexto investigado que são as relações de semelhança entre os DIAI e as categorias a priori definidas pelos seis focos da aprendizagem. Durante a leitura das transcrições, na medida em que encontrávamos trechos de comunicação relacionados com os focos do aprendizado científico informal, nós os 


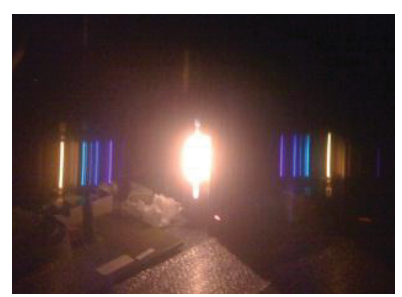

Fig. 1 - Espectro formado pela luz proveniente de uma lâmpada de hidrogênio.

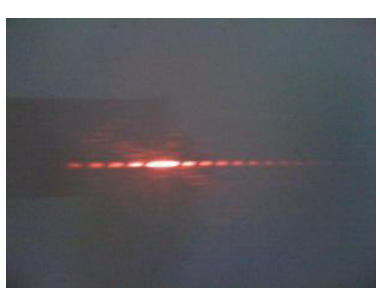

Fig. 4 - Difração em fenda simples por luz de laser.

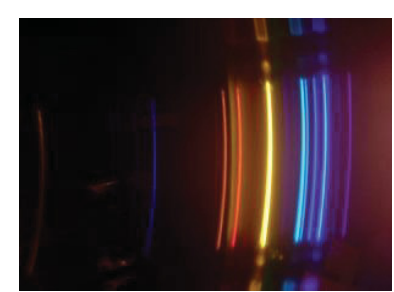

Fig. 2 - Espectro formado pela luz proveniente de uma lâmpada de hidrogê-

nio.

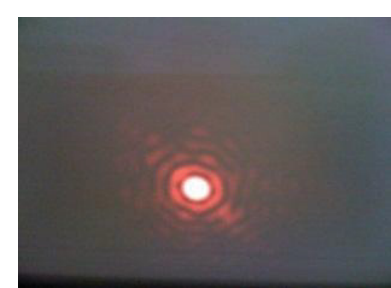

Fig. 3 - Difração em orifício por luz de laser.

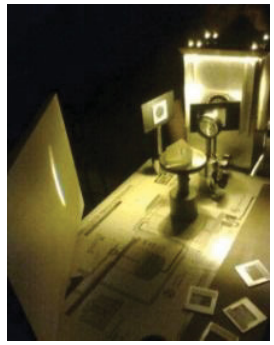

Fig. 5 - Montagem experimental com fenda, lentes, prisma.

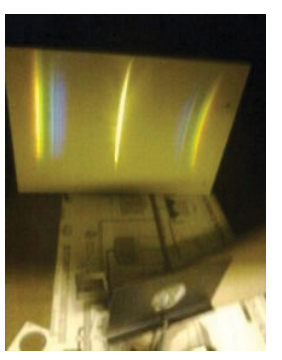

Fig. 6 -Imagem de difração em fenda.

separávamos e os codificávamos, constituindo assim conjuntos de unidades de busca e que se tornaram unidades de pesquisa. Deste movimento foi possível organizar o corpus em quarenta e cinco unidades a que foram atribuídos os seguintes códigos: U1 (unidade 1), U2 (unidade 2) até U45 (unidade 45). Como esses registros são constituídos por falas, cada período recebeu o código que contribuiu com a identificação de seu emissor: E1 para o estudante 1 (entenda-se 'estudante' pelo licenciando em Física); E2 para o estudante 2; F para o técnico do laboratório em que os experimentos eram desenvolvidos; P para o pesquisador que acompanhou todas essas atividades gravando-as em vídeo. $\mathrm{Na}$ apresentação dos DIAI, quando necessário, são inseridas 'notas de campo' que auxiliam na compreensão dos acontecimentos e, por conseguinte, de alguns assuntos abordados nas falas. Após a exposição do diálogo, incluímos uma breve justificativa para o enquadramento da unidade nos respectivos FAC. 


\section{Apresentação e análise dos dados}

Para compor esta seção, selecionamos apenas algumas das quarenta e cinco unidades de análise que, segundo nossa compreensão, são representativas do corpus.

Na sequência, apresentaremos a distribuição dos FAC em um gráfico e algumas interpretações que compõem nossas considerações relativas ao fenômeno em investigação. Ou seja, durante essas atividades realizadas por esses dois bolsistas do PIBID, ocorreu o aprendizado científico?

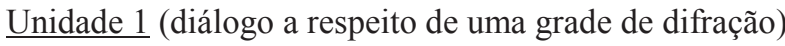

P: Você já viu uma grade de difração?

E2: Não nunca vi, deixa eu ver!

Nota: P mostra a grade e entrega para E2.

E2: Caraca!

P: Esta é de 300 linhas por milimetro.

E2: 300 linhas por milímetro...

P: Em cada milimetro tem 300 linhas.

O DIAI começa com a mostra de um dispositivo - a grade de difração -, objeto que faz parte do conjunto de equipamentos do laboratório em que E2 se encontra. O contato de E2 com o dispositivo novo (e seu significado) por meio da prática em laboratório nos coloca diante de uma situação de aprendizagem que está relacionada com o foco $\mathbf{5}$, que destaca o engajamento com a prática científica, focando o uso de ferramentas científicas. Também é possível evidenciar, neste fragmento de comunicação, o foco 1, por meio da expressão “caraca!", uma exclamação típica de admiração e de espanto.

Unidade 3 (diálogo sobre a observação de um espectro)

E1: É engraçado, é como se o espectro estivesse assim, na vertical.

P: Acho que assim, ela totalmente reta não tem difração.

E2: Se olha aqui dá para ver o espectro, pela rede de difração, mas pelo equipamento não dá para ver nada.

E1: Se eu alterar dá para ver aí?

Nota: E1 altera o tamanho da fenda, enquanto E2 olha no espectrômetro.

E2: Só está aumentando a fenda só. 
O termo "engraçado" nesta situação assume o significado de curiosidade e de estranhamento, por parte do E1, com relação ao fenômeno observado (um espectro), portanto, podemos considerar neste caso uma relação com o foco 1 . Na segunda parte do diálogo temos falas relativas ao processo experimental em que se altera uma variável (neste caso, o tamanho da fenda) e se observa a outra (o espectro), isso nos remete às competências científicas de investigação descritas no foco 3 da aprendizagem científica.

$\underline{\text { Unidade } 8}$ (diálogo relativo a uma grade de difração por reflexão)

E1: F, que tipo de espelho é este aqui?

F: Na realidade ele é meio polarizado, parece que é o tipo de decantação que é feito, decantação não, ele é pulverizado, igual àquele espelho da velocidade da luz. luz de novo?

E1: Ao falar nisso eu posso fazer aquele experimento da velocidade da

F: Para que você quer fazer isso? Aquela experiência é chata de fazer, mas eu deixo você fazer.

E1: É muito dez isso daqui! Física Moderna é o bicho mesmo! É uma coisa tão simples!

Na primeira parte do diálogo E1 interage com o técnico do laboratório, formulando uma pergunta sobre aquela ferramenta científica, fato que nos remete ao foco 5. Já na segunda parte do DIAI, E1 pede para o técnico uma oportunidade para repetir o experimento da velocidade da luz. Em nossas interpretações, esta atitude pode ser compreendida como uma demonstração de interesse de E1 pelo estudo da física, o que indica o foco 1. As expressões "é muito dez isto aqui", "Física Moderna é o bicho mesmo" e "é uma coisa tão simples" nos colocam diante dos focos 1 e 6, pois foi uma manifestação do bolsista E1, em que o envolvimento e a identidade com a ciência estão presentes.

$\underline{\text { Unidade } 9}$ (diálogo a respeito do papel da fenda na montagem experimental)

E2: Então como eu falei para você, este assunto eu ainda não tive na faculdade, esta parte de Física Moderna, dai eu tive que dar uma pesquisada, dai fui pesquisando no que eu fui tendo estas ideias, eu acredito no seguinte, quando tinham todas aquelas fotos, a diferença de uma foto com a fenda e uma foto só com o DVD não sei se você lembra, no DVD tinha o espectro todo assim, embaçado, todo junto né, eu acredito que a fenda, E2 se eu tiver errado você me corrige. 
Eu acredito que a fenda, ela limita a porção da onda que a gente vai analisar, será que isso está certo? O fato de a fenda atuar como um split. Porque ali no DVD a gente tinha todo o espectro grande na imagem, dai na fenda não deixava passar tudo, vamos dizer assim entendeu, dai deixava passar só um pedaço da onda, daí aparecia mais nítido assim e mais fácil de visualizar.

$P:$ E aí o que você acha E1?

E1: A fenda para a gente aqui serve só como colimador né [...].

E2: É colimador o nome?

E1: Sim. Ele serve só para, a meu ver, serve só para a gente trabalhar com um feixe mais nitido né, uma coisa mais, é o que você falou, a gente utiliza a fenda, a palavra certa seria, é que o nome dele já é colimador, é uma palavra... $[\ldots]$.

Nota: E2 faz anotações em uma folha.

No início deste diálogo, E2 relata sobre suas pesquisas referentes aos conteúdos que ainda não havia estudado durante a graduação, depoimento que podemos relacionar como o foco 1 , ou seja, ele estudou por livre escolha demonstrando assim motivação e interesse pessoal pela ciência. Na sequência, E2 utiliza informações estudadas e provenientes de buscas próprias, articulando suas ideias durante a explicação do fenômeno em observação e análise, nos permitindo relacionar o ocorrido com o foco 3. Destacamos ainda, neste DIAI, a aprendizagem do nome e da função do colimador presente nesta experiência, o que vincula o depoimento ao foco 5. Na continuidade E1 explica a função do colimador utilizando o termo nitidez, consideração que está relacionada com o foco 2 .

Unidade 11 (diálogo sobre a observação de um espectro)

P: O que você vê quando você põe isso aqui no olho?

E1: Eu vejo um espectro, começa lá com comprimento de onda no vermeIho, e vai até o violeta, dai para a esquerda eu consigo enxergar também o mesmo espectro, mas só que de uma forma mais apagada.

O DIAI é deflagrado pela pergunta de P para E1, quando questiona o que ele vê ao colocar uma rede de difração na direção da luz proveniente de uma lâmpada. A resposta do bolsista, breve e concisa, destaca a utilização da linguagem científica para descrever o fenômeno observado, no momento em que utiliza as palavras "espectro" e "comprimento de onda". Tal fato nos leva à relação com o foco 2 . 
Unidade 18 (diálogo relacionado às distâncias e às cores das linhas de um espectro)

E2: Eu estou tentando diferenciar bastante uma cor da outra, não sei para vocês, mas para mim, ali entre o violeta e o verde claro, tem duas linhas, não sei se vocês conseguem enxergar.

E1: Verde claro.

E2: O verde claro que eu digo é o que está mais perto do amarelo, ele é mais brilhante, tem duas linhazinhas ali né.

E1: Sim, aquela do lado do violeta eu pintei de azul.

E2: Eu também, ela é meio azul.

E1: Ela é meio azul.

E2: Você pode ver que a distância da violeta à última da direita e para a segunda linha ali ela é mais distante do que as duas verdes, tá vendo como que as das verdes são mais próximas?

E1: Sim, você reparou que do lado esquerdo desta verde claro tem uma linha bem fraquinha, do lado da verde claro, você reparou ou não?

E2: Do lado da verde claro? Qual?

E1: Do lado esquerdo.

E2: Do lado esquerdo, mas que cor ela é?

E1: É um verdinho mais bem apagado.

E2: Está quase colada nela.

E1: Este aí eu não consegui enxergar não.

Os bolsistas dialogavam enquanto analisavam um espectro através de uma rede de difração. Percebemos no diálogo que E1 e E2 tentaram diferenciar as cores das linhas, a intensidade e as distâncias entre elas. Estas são características principais que se pode observar em espectros deste tipo, portanto, importantes de serem destacadas. Essa percepção que eles buscam construir nos leva a acomodar essas comunicações no foco 3 . Ainda com relação a esse DIAI podemos evidenciar o envolvimento e a interação entre os estudantes em torno de uma prática laboratorial, que nos coloca diante do foco 5 .

Unidade 30 (diálogo a respeito das linhas de absorção)

E1: Sabe o que eu pensei agora, por exemplo, se a gente pegar uma outra lâmpada dessa sem estar ligada, a gente coloca ela aqui no meio, na frente, e ela vai ter um gás ali, e a radiação vindo dessa lâmpada da frente ela pode colidir 
com a radiação de dentro da outra, que está fora, e pode criar linhas diferentes, você concorda?

$P$ : Linhas de absorção?

E1: De absorção, exato.

Inicialmente, no diálogo, temos a formulação de uma hipótese por parte de E1, que prevê uma mudança no espectro, se houver também uma mudança na montagem experimental, fato relacionado ao foco 3 . Na continuidade, temos a introdução do termo "linhas de absorção", o que nos leva a observar uma situação de aprendizagem em que os sujeitos passam a conhecer termos e conceitos que compõem a linguagem científica, o que evidencia a presença do foco 2 nos depoimentos.

Unidade 31 (diálogos relativos às experiências com os espectros)

Nota: E1 está falando sobre as atividades de experimentação em laboratório.

E1: Eu achei muito legal, bacana!

P: Por que você achou legal?

E1: A observação das linhas, embora a gente consiga ver difração olhando no CD e tal, mas a gente não consegue compreender muito bem a Física ainda, através dos experimentos a gente não consegue compreender ainda, mas é bacana, a gente até tentou esboçar algumas ideias ali no quadro e tal, e saber que a luz se comporta, não só a luz, a matéria, emitindo radiação.

E2: Então, este negócio que ele falou é interessante, porque na verdade a gente lida com isso, a gente pega um CD, a gente pega um DVD, a gente tem um contato com aquele espectro, só que a gente não entende ao certo a aplicação disso, na realidade, por que que aparece ali todo o espectro, porque é uma luz branca que contém todas as cores no caso, mas se fosse uma luz assim (aponta para a lâmpada de mercúrio) tipo de um elemento único, com certeza iriam aparecer só algumas mais nítidas, podia até aparecer todas, mas algumas mais nítidas.

A utilização das palavras "bacana", "legal", "interessante" pelos licenciandos de Física indica um interesse, fato que nos permite relacionar essas falas ao foco 1. No entanto, no relato do E1 este interesse é seguido de uma preocupação com a compreensão completa do experimento, ou seja, "saber como a luz se comporta”, essa complementação apresentada por ele nos leva a relacionar suas argumentações com o foco 3. Avançando um pouco mais neste diálogo, E2 explica o 
porquê do espectro contínuo observado no DVD, fato que pode ser acomodado junto ao foco 2.

Unidade 42 (diálogo sobre a história da Física)

E1: Para incentivá-los a gente faz uma abordagem histórica do estudo da luz... Para mostrar para eles que não é só a luz e tal...

E2: É, a gente começa falando uma coisa do tipo, uma das maiores dúvidas da Física de todos os tempos foi saber se a luz é uma onda ou uma partícula. Hoje nós vamos dar um exemplo que trata a luz como partícula. Entendeu? Para dar um pouco mais de ênfase no assunto.

Neste breve diálogo, os estudantes falam sobre a dualidade onda-partícula, isso nos coloca diante de argumentações relativas à história das ideias da Física, situação que compreendemos que esteja relacionada ao foco 4 , em virtude de a ciência ser um empreendimento cultural - "não é só a luz e tal..." (E1).

Cabe ressaltar que o procedimento de separar cada frase, identificando nelas as relações com os FAC, demandou muito tempo neste processo investigativo. No entanto, como puderam ser observados, os DIAI analisados revelam a presença das diferentes dimensões da aprendizagem científica. Tendo por base todos os DIAI ocorridos (no laboratório) durante as aproximadas 10 horas de gravação, foi possível construir um perfil de aprendizagem para cada sujeito.

No Quadro 2, trazemos o resultado da distribuição das unidades de pesquisa - que identificam e delimitam os DIAI - nos focos de 1 a 6 . A acomodação realizada seguiu os seguintes critérios: primeiro distinguimos qual estudante estava envolvido no DIAI daquela unidade; depois disso, discriminamos quais os focos presentes naquele DIAI; por último, alocamos as unidades nos focos de cada um dos estudantes, ou seja, caso em um mesmo DIAI os dois bolsistas se manifestem, essa unidade é alocada na linha do Quadro 3 de cada um deles. Um exemplo pode auxiliar nesta compreensão: retomemos à Unidade 31, apresentada anteriormente; naquele DIAI temos presentes os focos 1, 2 e 3, pela interpretação realizada tem-se que E2 se manifesta com relação aos três focos (como pode ser observado na terceira linha do quadro a seguir - U31 - serão encontrados nas três células relativas a esses três focos), contudo, E1 em suas manifestações somente apresenta relação com os focos 1 e 3, o que, por conseguinte, permite a alocação do código U31 somente nas duas células relativas a esse dois focos na segunda linha que busca apresentar o perfil deste bolsista do PIBID. 
Quadro 2 - Distribuição das 45 unidades de análise nos FAC.

\begin{tabular}{|c|c|c|c|c|c|c|}
\hline Bolsista & Foco 1 & Foco 2 & Foco 3 & Foco 4 & Foco 5 & Foco 6 \\
\hline E1 & $\begin{array}{l}\text { U3; U7; } \\
\text { U8; } \\
\text { U29; } \\
\text { U31 }\end{array}$ & $\begin{array}{l}\text { U6; U9; } \\
\text { U10; } \\
\text { U11; } \\
\text { U13; } \\
\text { U32; } \\
\text { U37; U40 }\end{array}$ & $\begin{array}{l}\text { U3; U14; } \\
\text { U17; } \\
\text { U29; } \\
\text { U30; } \\
\text { U31; U32 }\end{array}$ & U42 & $\begin{array}{l}\text { U2; U8; } \\
\text { U15; } \\
\text { U18; } \\
\text { U30; } \\
\text { U35; } \\
\text { U36; } \\
\text { U38; U41 }\end{array}$ & $\begin{array}{l}\text { U8; } \\
\text { U13; } \\
\text { U33; } \\
\text { U43 }\end{array}$ \\
\hline$\overline{\mathrm{E} 2}$ & $\begin{array}{l}\text { U1; U9; } \\
\text { U16; } \\
\text { U17; } \\
\text { U19; } \\
\text { U23; } \\
\text { U25; } \\
\text { U31 }\end{array}$ & $\begin{array}{l}\text { U31; } \\
\text { U34; } \\
\text { U44; } \\
\text { U45; } \\
\text { U46 }\end{array}$ & $\begin{array}{l}\text { U3; U5; } \\
\text { U9; U12; } \\
\text { U14; } \\
\text { U17; } \\
\text { U18; } \\
\text { U20; } \\
\text { U22; } \\
\text { U26; } \\
\text { U27; } \\
\text { U28; U31 }\end{array}$ & $\begin{array}{l}\text { U24; } \\
\text { U42; } \\
\text { U43 }\end{array}$ & $\begin{array}{l}\text { U1; U4; } \\
\text { U9; U18; } \\
\text { U21; } \\
\text { U26; } \\
\text { U39 }\end{array}$ & $\begin{array}{l}\text { U25; } \\
\text { U39 }\end{array}$ \\
\hline
\end{tabular}

Diante dessa acomodação, o que podemos concluir sobre esses licenciandos em Física, quando focamos no processo de aprendizagem científica em situações informais de aprendizagem, possibilitadas pela participação em atividades no laboratório de espectroscopia? A nosso ver fica evidente que os estudantes E1 e E2 se engajaram com maior frequência nos fazeres e nas discussões que se pautavam no raciocínio científico e na prática científica, conforme definido pelo foco 3 e foco 5 , respectivamente.

O foco em que houve menor incidência de argumentações, segundo as unidades de comunicação interpretadas, foi o foco 4 , aquele que se estrutura sobre os posicionamentos dos depoentes em relação à reflexão sobre a ciência. $\mathrm{O}$ gráfico a seguir ilustra, para cada um dos acadêmicos, essa distribuição das unidades de pesquisa nos focos.

Ao observarmos o gráfico e voltarmos nossas atenções para cada um dos pesquisados particularmente, vemos que para $\mathrm{E} 1$ a distribuição ocorre com certa proximidade de frequência em três focos: foco 2 - relativo ao conhecimento científico; foco 3 - que destaca o raciocínio científico; foco 5 (com certo crescimento em relação aos demais) - relacionado à prática científica. Para os demais focos a incidência de manifestações, diante da interpretação e construção da unidade de pesquisa, foi relativamente menor. 


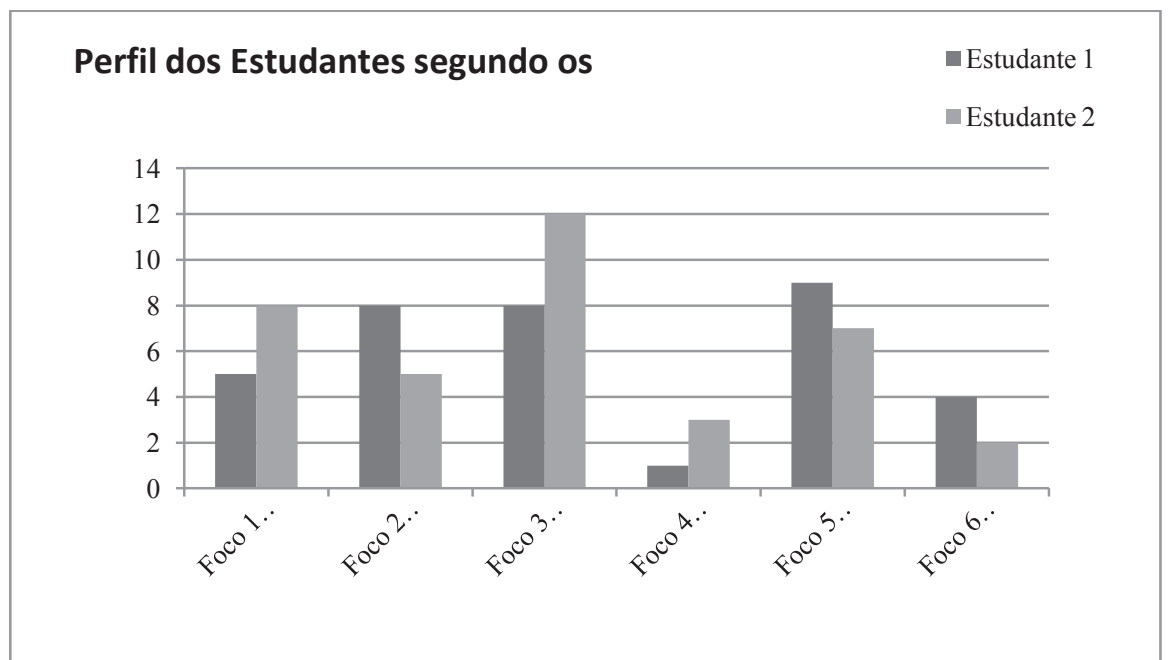

Gráfico 1 - Distribuição dos diálogos de cada estudante nos FAC.

Buscando observar da mesma forma E2, vemos que há uma incidência muito maior de suas falas no foco 3 - raciocínio científico, e outros dois focos com ênfase menor, mas com destaque em relação aos demais, são eles: foco 1 (interesse pela ciência) e foco 5 .

Observando-os conjuntamente, podemos concluir que duas dimensões do aprender estiveram mais presentes no processo investigado e elas poderiam ser descritas por algumas características que emergem das comunicações: formular, responder perguntas, explorar a situação experimental, explicar ideias, prever, concluir, criar hipóteses (como representativas do raciocínio científico - foco 3 para a dupla investigada); a prática científica em grupo com destaque para a utilização de ferramentas - foco 5.

É possível também, nesta leitura integrada de ambos, evidenciar as diferenças entre estes dois graduandos: enquanto o E1 participou mais dos DIAI relacionados aos focos 2, 3 e 5, E2 participou daqueles DIAI que foram acomodados nos focos 1,3 e 5 . Constituindo assim algumas diferenças e destaques aos seus perfis de aprendizagem científica.

\section{Considerações finais}

Nesta investigação consideramos o PIBID como uma configuração informal de aprendizagem científica. Desta forma, as situações de aprendizagem resul- 
taram de experiências individuais de E1 e E2, atividades não estruturadas, experimentações e diálogos sobre ciência, ocorridos durante cinco encontros em laboratório de espectroscopia. Optamos por gravar tais interações, transcrever e selecionar os diálogos de ensino e aprendizagem informal (DIAI), conforme definido em Arruda et al. (2013). Após a pré-análise e a exploração do material, etapas que compõem os procedimentos da Análise de Conteúdo, partimos para a interpretação dos diálogos tendo como base os seis focos do aprendizado científico informal (FAC).

As comunicações analisadas mostram a presença de vários focos da aprendizagem científica durante todo o processo de experimentação e utilização do laboratório por parte dos graduandos em Física. Portanto, retomando a questão inicial e confrontando-a com os resultados que obtemos (Quadro 2 e Gráfico 1), consideramos que ocorrem aprendizagens científicas informais, no contexto do PIBID, e que é possível identificá-las utilizando: I) a Análise de Conteúdo das comunicações, como ferramenta para interpretar aquilo que é falado durante o processo e II) os FAC como categorias a priori que evidenciam a aprendizagem científica.

Estes resultados nos conduzem a novas questões que orientarão nossas futuras pesquisas; citamos duas delas: De que forma o perfil constituído para cada licenciando pode ser utilizado para melhorar as aprendizagens subsequentes? Como os focos da aprendizagem científica podem ser incorporados no planejamento das atividades em laboratório, pelos próprios graduandos?

A combinação dos FAC com os procedimentos de Análise de Conteúdo conduziu nosso estudo sobre as comunicações dos estudantes, no momento do aprender. Como visto, os focos abordam não somente a aprendizagem de conteúdos (tão evidenciada atualmente na grade curricular, nas ementas e nos programas das licenciaturas), mas também o interesse, o raciocínio, a reflexão, a prática e a identificação do estudante com a ciência, o que encaminhou de maneira mais estruturada nossa analise sobre a aprendizagem científica informal.

Nesta pesquisa buscamos definir e separar os focos. No entanto, nos deparamos com a ambiguidade na significação das unidades de análise, pois em alguns casos possuem mais de uma interpretação. Ainda assim, consideramos frutífero o movimento de categorização como uma possível forma de compreensão do processo, o que para nós representa um tipo de "focalização". Desta forma pensamos ser possível abordar e discutir sobre o complexo processo do que é aprender ciência em contextos informais, consequentemente do que é analisar e avaliar esta aprendizagem. Mais pesquisas sobre o referencial podem refinar ainda mais as categori- 
as, explorando as diferentes qualidades de cada foco, assim como os procedimentos para a identificação, análise e apresentação de resultados.

Consideramos a possibilidade de exposição e discussão dos perfis elaborados na pesquisa, com os próprios estudantes com o objetivo de: contribuir com a construção da consciência de si, sobre a própria maneira de aprender; e desenvolver um tipo de autonomia que o permitirá escolher com base em sua própria maneira, aquilo que quer aprender, características fundamentais da aprendizagem científica informal.

\section{Referências}

ARRUDA, S. M. A teoria atômica de Bohr. UEL: Apostila. Laboratório de Física Moderna, 1998.

ARRUDA, S. M.; VILLANI, A.; UENO, M. H.; DIAS, V. S. Da aprendizagem significativa à aprendizagem satisfatória na educação em ciências. Caderno Brasileiro de Ensino de Física, Florianópolis, v. 21, p. 194-223, 2004.

ARRUDA, S. M.; PASSOS, M. M.; FREGOLENTE, A. Focos da Aprendizagem Docente. Alexandria: Revista de Educação em Ciência e Tecnologia, Florianópolis, v. 5, n. 3, p. 25- 48, 2012.

ARRUDA, S. M.; PASSOS, M. M.; PIZA C. A.; M.; FELIX, R. A. B. O aprendizado científico no cotidiano. Ciência \& Educação. Bauru, v. 19, n. 2, p. 481-498, 2013.

BANKS, J. A. et al. Learning in and out of school in diverse environments: Lifelong, life-wide, life-deep. Seattle: Center for Multicultural Education, University of Washington, 2007.

BARDIN, L. Análise de conteúdo. Lisboa: Edições 70, 2004.

BRASIL. Decreto $n^{0} 7.219$, de 24 de junho de 2010. Dispõe sobre o Programa Institucional de Bolsa de Iniciação à Docência - PIBID e dá outras providências. Diário Oficial da União, n.120, seção 1, p. 4-5, 2010.

DUIT, R.; TREAGUST, D. Conceptual Change - A powerful framework for improving science teaching and learning. International Journal of Science Education, v. 25, p. 671-688, 2003. 
EUROPEAN COMMISSION. Communication from the Commission: Making a European Area of Lifelong Learning a Reality. Nov. 2001. Disponível em: $<$ http://www.bologna-berlin2003.de/pdf/MitteilungEng.pdf $>$. Acesso em: 09 jan. 2013.

FALK, J.; DIERKING, L. Learning from museums: visitor experience and making a meaning. Laham: AltaMira, 2000.

LABURÚ, C. E.; SILVA, O. H. M. Multimodos e múltiplas representações: fundamentos e perspectivas semióticas para a aprendizagem de conceitos científicos. Investigações em Ensino de Ciências, Porto Alegre, v. 16, n. 1, p. 7-33, 2011.

MORAES, R.; GALIAZZI, M. do C. Análise textual discursiva. Ijuí: Ed. Unijuí, 2007.

MORTIMER, E. F. Conceptual change or conceptual profile change? Science \& Education, v. 4, n. 3, p. 265-287, 1995.

NATIONAL RESEARCH COUNCIL. Learning science in informal environments people, places, and pursuits. Committee on learning science in informal environments, national research council of the national academies. Washington, 2009. Disponível em: <http://www.nap.edu/catalog/12190.html>. Acesso em: 4 jan. 2013.

OSTERMANN, F.; MOREIRA, M. A. Uma revisão bibliográfica sobre a área de pesquisa "física moderna e contemporânea no ensino médio". Investigações em Ensino de Ciências, Porto Alegre, v. 5, n. 1, p. 23-48, 2000.

POSNER, G. J.; STRIKE, K. A.; HEWSON, P. W.; GERTZOG, W. A. Accommodation of a Scientific Conception: toward a theory of conceptual change. Science Education, v. 66, n. 2, p. 221-227, 1982.

QUEIROZ, G. R. P. C.; LIMA, M. C. A. Conhecimento científico, seu ensino e aprendizagem: atualidade do construtivismo. Ciência e Educação, v. 13, n. 3, p. 273-291, 2007. 